\title{
Morfometría, estratigrafía, petrografía y geoquímica del cono de escoria El Morro, municipio La Argentina (Huila, Colombia)
}

Lyna M. Rodríguez ${ }^{*}$; John J. Sánchez ${ }^{2}$

DOI: http://dx.doi.org/10.18273/revbol.v40n3-2018003 @ (1)

Forma de citar: Rodríguez, L.M., y Sánchez, J.J. (2018). Morfometría, estratigrafía, petrografía y geoquímica del cono de escoria El Morro, municipio La Argentina (Huila, Colombia). Boletín de Geología, 40(3), 49-65. DOI: 10.18273/revbol.v40n3-2018003.

\section{RESUMEN}

El presente trabajo es un aporte al conocimiento geológico del Centro Eruptivo El Morro (CEM), ubicado en el departamento de Huila (Colombia), mediante el análisis morfométrico del edificio, levantamiento estratigráfico de los depósitos piroclásticos, y el análisis petrográfico y geoquímico de los clastos juveniles. Los depósitos piroclásticos fueron caracterizados en cuanto a la geometría de las capas, variaciones texturales y granulométricas, mineralogía, y composición química de roca total. El CEM es un cono de escorias simple y bien preservado, por lo que se presupone relativamente joven.

Es un centro eruptivo máfico compuesto principalmente por depósitos piroclásticos, agrupados en tres paquetes de acumulación distinguibles a escala de afloramiento por la gradación variable normal e inversa. Los clastos principalmente juveniles que conforman los paquetes estratigráficos varían en tamaño entre ceniza y bomba. La petrografía y geoquímica de los clastos del CEM indican emisión de un magma basáltico. A partir de las relaciones morfométricas y los diagramas de discriminación del ambiente geotectónico se concluyó que los fragmentos analizados sugieren afinidad con arco continental y su ambiente de formación está asociado a subducción.

Palabras clave: Cono de escoria El Morro; estratigrafía; geoquímica; morfometría; petrografía.

\section{Morphometry, stratigraphy, petrography, and geochemistry of El Morro scoria cone, La Argentina municipality (Huila, Colombia)}

\begin{abstract}
This work is a contribution to the geological knowledge of El Morro eruptive center (CEM), located in the State of Huila (Colombia), by means of the morphometric analysis of the edifice, stratigraphic survey of pyroclastic deposits, and petrographic and geochemical analysis of juvenile clasts. The pyroclastic deposits were characterized in terms of the geometry of the layers, textural and granulometric variations, mineralogy, and whole-rock chemistry. The CEM is a simple and well-preserved scoria cone, and thus it is considered young.

It is a mafic eruptive center, composed by pyroclastic deposits, grouped in three distinguishable accumulation packages at the outcrop scale by their normal-to-reverse variable grading. The mostly juvenile clasts that make up the stratigraphic packages vary in size between ash and bomb. The petrography and geochemistry of the CEM clasts indicate the emission of a basaltic magma. From the morphometric relationships and the discrimination diagrams for the geotectonic environment, it was concluded that the fragments analyzed suggest affinity with continental arc basalts and their formation environment is associated to subduction.
\end{abstract}

Keywords: El Morro scoria cone; stratigraphy; geochemistry; morphometry; petrography.

\footnotetext{
1 Departamento de Geociencias, Universidad Nacional de Colombia, Bogotá, Cundinamarca, Colombia. (*)lymrodriguezpe@unal.edu.co

${ }^{2}$ Departamento de Geociencias y Medio Ambiente, Universidad Nacional de Colombia, Medellín, Antioquia, Colombia. jjsanchezag@unal.edu.co
} 


\section{INTRODUCCIÓN}

El Centro Eruptivo El Morro (CEM), es una geoforma volcánica ubicada en la Cordillera Central de Colombia, en cercanías del municipio de La Argentina, en el departamento del Huila (FIGURA 1). Escasos estudios anteriores lo han mencionado de manera muy general como un cono de escorias (Kroonenberg et al., 1981; Robertson et al., 2002). Los conos de escoria son volcanes relativamente pequeños pero muy comunes en la Tierra, generalmente formados a partir de la erupción de magma basáltico de baja viscosidad durante erupciones estrombolianas o hawaianas (Sigurdsson et al., 2000).

Los depósitos de los conos de escoria, que en general son formados por caídas piroclásticas, predominantemente en forma de proyectíles balísticos, se distinguen por presentar capas gruesas y delgadas, generalmente macizas, clastosoportadas y moderadamente seleccionadas, con bombas y lapilli juveniles con diferentes vesicularidades y densidades, acumulados principalmente en el mismo edificio volcánico aunque con posibilidades de alcanzar hasta aproximadamente $10 \mathrm{~km}$ de la fuente (Sigurdsson et al., 2000).

En el presente trabajo se presentan resultados de la morfología, estratigrafía, petrografía y geoquímica de roca total de los productos aflorantes en la denominada “Cantera El Morro” y alrededores, como una contribución al estudio del vulcanismo en la región.

\section{Localización}

El CEM se ubica en el flanco oriental de la Cordillera Central de Colombia, $6 \mathrm{~km}$ al occidente del municipio de La Argentina, en el departamento del Huila ( $X=782.391$ E, $Y=734.037$ N, Sistema de Coordenadas Magna Sirgas, Datum Bogotá; Longitud -76.03, Latitud 2.19 Datum WGS84), con altitud en cima de 1800 m.s.n.m. (FIGURA 1). Según la nomenclatura del Instituto Geográfico Agustín Codazzi, el CEM se encuentra en la plancha 365 COCONUCO (Marquínez et al., 2003).

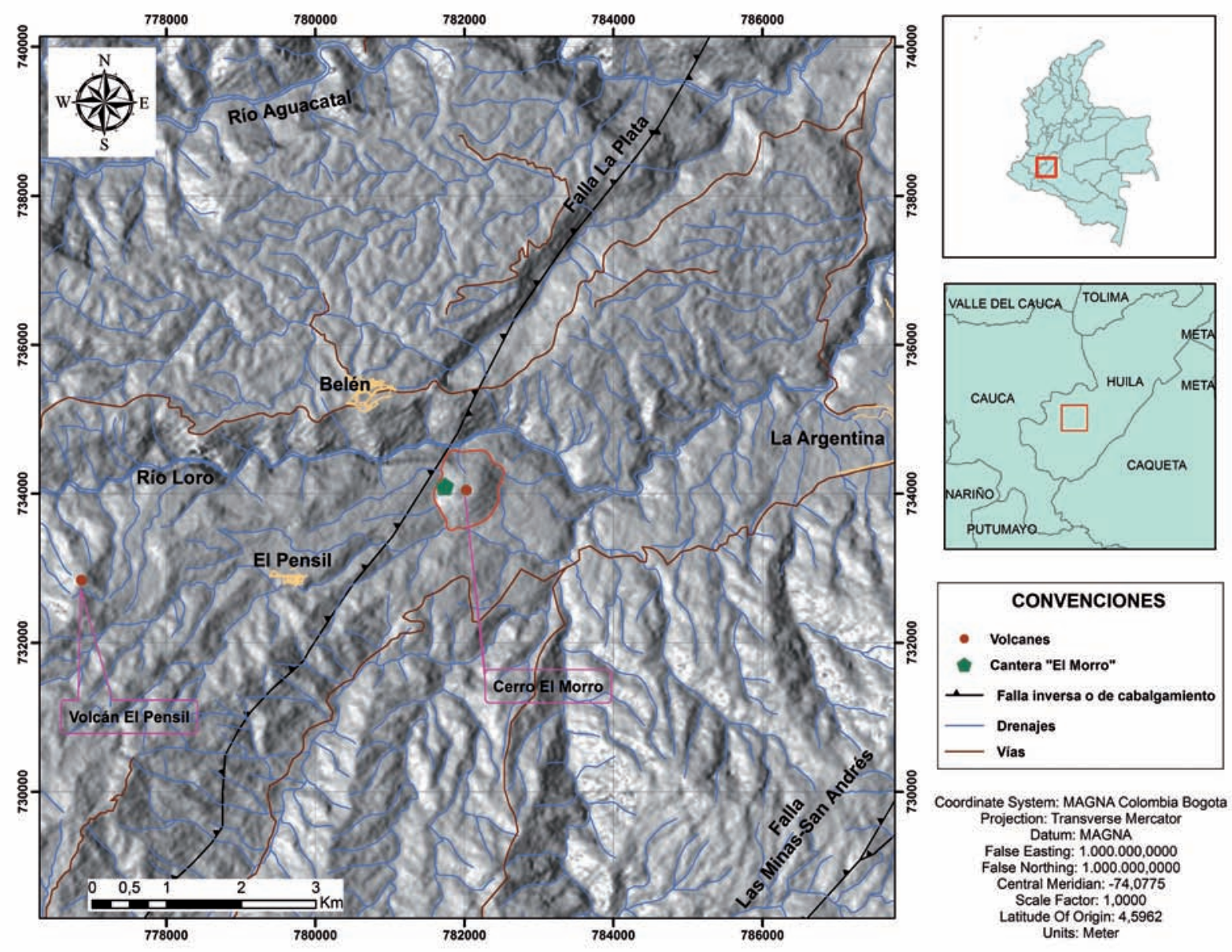

FIGURA 1. Mapa de localización área de estudio e imagen de relieve sombreado obtenida mediante procesamiento de datos de la misión ALOS PALSAR (JAXA, 2011), con resolución espacial de 12 metros/pixel. 


\section{Geología}

Kroonenberg et al. (1981) indican que los productos asociados al CEM alcanzaron distancias hasta de $3 \mathrm{~km}$ alrededor del cráter. A partir del aspecto poco erosionado del edificio los autores sugirieron que el CEM puede representar la última fase del vulcanismo basáltico de la zona al este de la Cordillera Central.

Las escorias del CEM yacen discordantemente sobre unidades más antiguas, como el Batolito de Ibagué con edad correspondiente al Jurásico Medio - Jurásico Tardío, el cual está compuesto por variaciones de rocas entre granito, granodiorita, cuarzomonzodiorita y monzodiorita (Núñez 1998 en Velandia et al., 2001). Además, los depósitos pirocásticos del CEM suprayacen localmente a la Formación Guacacallo, definida por Kroonenberg et al. (1981), compuesta por tobas vítreas de color gris claro, vítrea, poco consolidadas, de edad Neógeno Tardío (Marquínez et al., 2003). A su vez, el CEM está incluido en la unidad denominada QvmEscorias El Morro, de edad Cuaternario Tardío con base en la posición estratigráfica, definida por Marquínez et al. (2003). Sin embargo, no se han reportado edades radiométricas que lo demuestren y probablemente, tuvo actividad en tiempos prehistóricos como fue mencionado por primera vez por Hernández y Tello (1978) en Kroonenberg et al. (1981).

Flórez (2003) incluyó el CEM dentro de un "grupo" (op.cit) volcánico de siete centros eruptivos basálticos denominado La Plata - San Agustín, en el sector suroccidental del Huila, en los municipios de La Argentina, La Plata, San Agustín y San José de Isnos. De otra parte, Zuluaga y Borrero (2012) lo redefinieron como parte del Campo Volcánico San Agustín, dentro del sector denominado Argentina-Merenberg.

\section{Marco Tectónico}

El área correspondiente a la Plancha 365 Coconuco comprende los dos flancos y el eje de la Cordillera Central, en su parte sur y la parte suroccidental del Valle Superior del Magdalena. La región morfoestructural donde se encuentra el CEM es la oriental, definida por Marquínez et al. (2003). Dentro de esta región limitada al occidente por la Falla Inzá, se encuentran las Fallas la Plata y Las Minas (FIGURA 1).

La Falla La Plata hace parte del Sistema de Fallas Chusma (Dixon, 1953 en Velandia et al., 1996). El comportamiento de esta falla es inverso, con vergencia al sureste y probablemente con una componente de rumbo sinestral (Montes, 2001). Algunos autores afirman que es posible que esta falla inversa aumente su inclinación en profundidad, por la presencia de volcanes alcalinos como El Morro (FIGURA 1), los cuales pueden estar relacionados con su trazo. Sin embargo, esto implicaría que la falla alcanza el manto superior, por lo que es preferible pensar que el vulcanismo alcalino se encuentra relacionado con lineamientos de dirección NW-SE identificados en la plancha 365. La Falla La Plata se encuentra cubierta por los sedimentos volcanoclásticos de la Formación Guacacallo en cercanías de la población de Belén; adicionalmente, controla el cauce del río La Plata (Marquínez et al., 2003).

\section{METODOLOGÍA}

\section{Revisión bibliográfica}

Comprendió la revisión de los estudios previos sobre el área de estudio (Kroonenberg et al., 1981; Flórez, 2003; Marquínez et al., 2003) y la recopilación de bibliografía acerca del análisis morfométrico de conos a nivel mundial (e.g Campo Calatrava, España, Becerra y Doniz, 2008; Mt. Etna, Italia, Favalli et al., 2009; Cono Pelagatos, México, Flores, 2009).

\section{Trabajo de campo}

Se llevó a cabo una salida de campo de cuatro días (julio de 2016) durante la cual: (1) se inspeccionó el área general del CEM y se recorrieron todos los accesos conocidos; (2) se reconoció y describió la morfología del cuerpo volcánico; (3) se describió el afloramiento de la "Cantera El Morro" y se encontraron nuevos afloramientos en la zona; (4) se realizaron las columnas estratigráficas y (5) se recolectaron muestras en volumen (bulk sampling), $>1 \mathrm{~kg}$ en cada uno de los 16 niveles identificados dentro de tres paquetes estratigráficos (P-01, P-02 y P-03), los cuales fueron definidos como acumulaciones entre paleosuelos incipientes. Adicionalmente se recolectaron seis muestras, 2 de cada paquete estratigráfico (ver ubicación FIGURA 2), las cuales eran clastos individuales, para realizar los análisis químicos.

\section{Análisis morfométrico}

Para el análisis morfométrico se usaron imágenes de relieve sombreado obtenidas a partir de datos captados por el satélite ALOS PALSAR (JAXA, 2011), con resolución espacial de 12 metros/píxel y un Modelo de Elevación Digital (Digital Elevation Model-DEM). 
Tanto las imágenes como el DEM se procesaron e interpretaron con el programa de Sistema de Información Geográfica (SIG) ArcGis (ESRI, versión 10.2). En la cuantificación de parámetros morfométricos se siguieron las parametrizaciones clásicas para conos de escoria y edificios volcánicos simples (Porter, 1972; Wood, 1980), junto con el análisis de un modelo digital del terreno (Favalli et al., 2009; Fornaciai et al., 2012). El volumen del CEM se estimó de manera simple al aplicar la fórmula geométrica para el volumen de un cono truncado y mediante la fórmula para volumen de un cono de escoria según el método utilizado por Flores (2009).

\section{Estratigrafía}

En cada sitio se realizó inicialmente una descripción general del mismo, para proceder a la descripción detallada de los paquetes estratigráficos en afloramiento. En esta descripción se determinaron las estructuras, espesores y geometría de las capas, estructuras sedimentarias, la selección, el tamaño, la gradación, el soporte y la morfología de clastos. La sección tipo se levantó en el flanco $\mathrm{W}$ del edificio (FIGURA 2).

Los paquetes estratigráficos fueron definidos como acumulaciones entre paleosuelos incipientes. Se escogió un (1) $\mathrm{kg}$ de muestra de cada nivel definido dentro de cada paquete, según la variación de gradación normal a inversa, teniendo en cuenta que tuvieran el mínimo grado de meteorización, y que hubiera un cambio de granulometría notable, en los estratos que tuvieran mejor marcada esta gradación.

El trabajo de laboratorio consistió en el tamizado de las muestras en seco, para definir su clasificación por tamaño de grano según la nomenclatura para depósitos piroclásticos (White y Houghton, 2006).

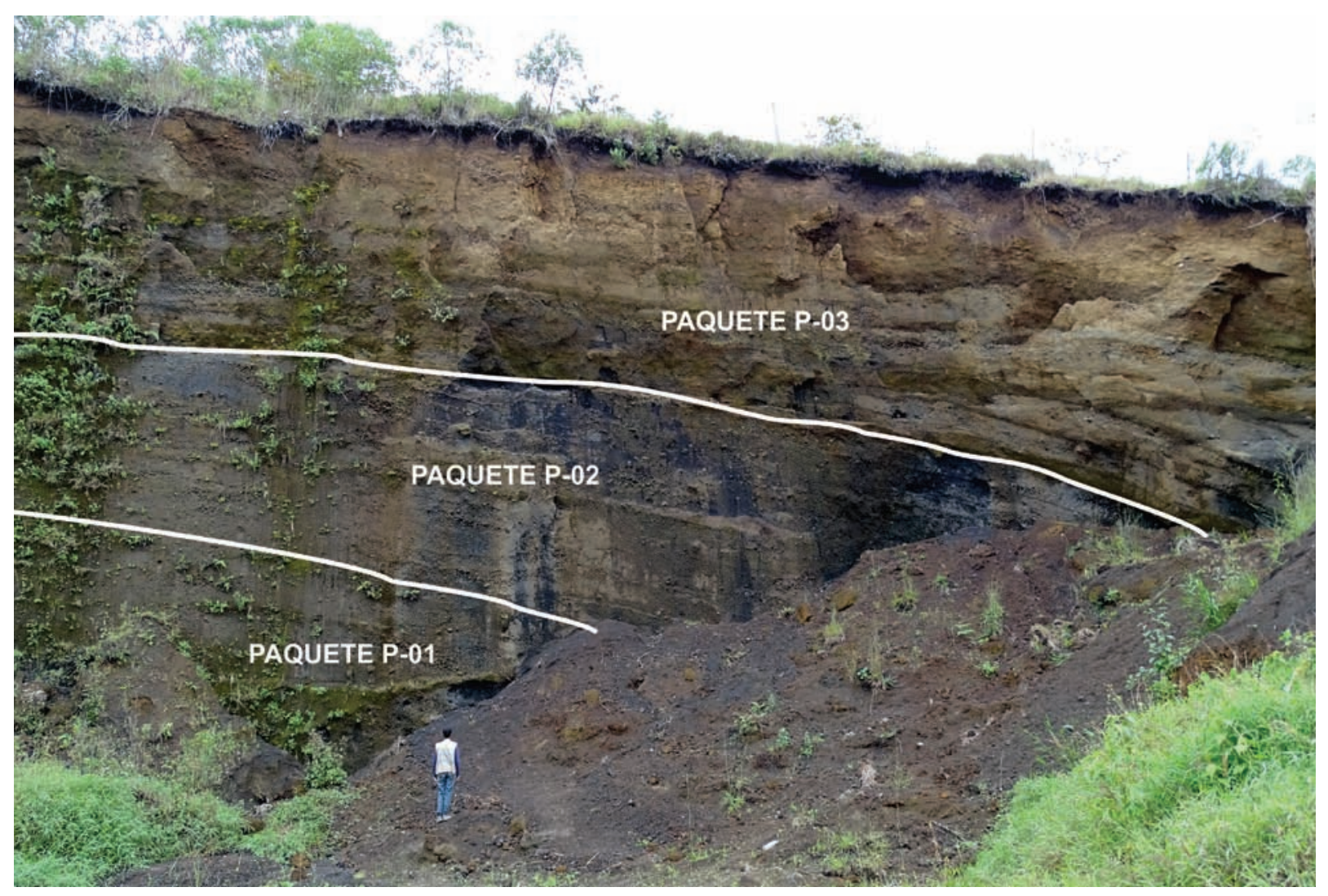

FIGURA 2. "Cantera El Morro". Afloramiento en el flanco W del CEM, señalando los paquetes estratigráficos, identificados según las variaciones en geometría y textura de los clastos de escoria. 


\section{Análisis petrográfico}

Se realizó la descripción y clasificación petrográfica, mediante el análisis de secciones delgadas de tres clastos individuales de cada uno de los paquetes descritos en este trabajo, del paquete P-01, la muestra UN-CEM-01, del P-02 la muestra UN-CEM-02 y del P-03 la muestra UN CEM-03 (FIGURA 5); ya que eran bastante homogéneos y no se veía cambio en la mineralogía de las muestras de mano, además, presentaban un bajo grado de meteorización.

\section{Análisis químicos}

Para este análisis, se utilizaron seis clastos individuales, dos de cada uno de los paquetes, CEM-01 y CEM-02 del paquete P-01, CEM-03 y CEM-04 del paquete P-02 y CEM-05 y CEM-06 del paquete P-03. Los clastos fueron cortados y triturados con un molino de bolas de ágata, fueron secados y se generaron seis pastillas prensadas de $37 \mathrm{~mm}$ de diámetro para análisis de química de roca total (elementos mayores y algunos traza) realizados en el laboratorio de Fluorescencia de Rayos X del Departamento de Geociencias - Universidad Nacional de ColombiaSede Bogotá. El análisis semicuantitativo se realizó con el software SemiQ, haciendo 11 barridos, con el fin de detectar todos los elementos presentes en la muestra, excluyendo $\mathrm{H}, \mathrm{C}, \mathrm{Li}, \mathrm{Be}, \mathrm{B}, \mathrm{N}, \mathrm{O}$ y los elementos transuránicos. Los datos fueron procesados con el programa GCDkit versión 5.0 (Janoušek et al., 2000). Adicionalmente, se realizaron análisis químicos de suelos en el Laboratorio de Aguas y Suelos de la Facultad de Agronomía- Universidad Nacional de Colombia-Sede Bogotá para determinar el grado de desarrollo del suelo encontrado en el contacto entre los paquetes P-02 y P-03.

\section{RESULTADOS}

\section{Morfometría}

Aunque se pueden localizar referencias de análisis morfométricos aplicados al análisis de volcanes de más de tres décadas, en Colombia estos estudios sólo se han utilizado muy recientemente en el análisis del cono La Guaca (Nariño) (Pérez, 2012) y múltiples conos asociados a la Caldera de Paletará (Samacá, 2016). Porter (1972), Settle (1979) y Wood (1980) definen los aspectos morfométricos que se deben tener en cuenta para describir conos de escoria, basados en análisis estadísticos de campos de volcanes monogenéticos en diferentes partes del mundo. Definen los parámetros: $\mathrm{A}_{\text {со }}$ (altura del cono), $\mathrm{D}_{\text {со }}$ (diámetro basal del cono) y $\mathrm{D}_{\text {cr }}$ (diámetro del cráter). Otros parámetros que se estiman para un análisis más exacto son los propuestos por Becerra y Doniz (2008) quienes sugieren medir la profundidad del cráter $\left(\mathrm{P}_{\mathrm{cr}}\right)$, la pendiente máxima del aparato eruptivo $\left(\mathrm{P}^{\circ}\right)$, la superficie $\left(\mathrm{S}, \mathrm{km}^{2}\right)$ y el volumen $\left(\mathrm{V}, \mathrm{km}^{3}\right)$. Con estos parámetros se realizan diferentes correlaciones morfométricas: altura del edificio/diámetro del cono $\left(\mathrm{A}_{\mathrm{co}} / \mathrm{D}_{\mathrm{co}}\right)$, diámetro del cráter/diámetro basal $\left(\mathrm{D}_{\mathrm{cr}} / \mathrm{D}_{\mathrm{co}}\right)$, la relación entre diámetros medios máximo y mínimo, o elongación del edificio $\left(\mathrm{DM}_{\mathrm{co}} / \mathrm{dm}_{\mathrm{co}}\right)$, e índices como la separación y el agrupamiento (Porter, 1972) (FIGURA 3).

A nivel global, se considera que los diámetros basales presentan valores de $0,25<\mathrm{D}_{\text {со }}<2,5 \mathrm{~km}$, con una mediana de $0,8 \mathrm{~km}$; mientras que las alturas de conos ( $\mathrm{A}_{\text {co }}$ ) estarían alrededor de $0,18 \mathrm{D}_{\text {со }}$ y los diámetros de cráteres $\left(\mathrm{D}_{\mathrm{cr}}\right)$ serían del orden de $0,4 \mathrm{D}_{\mathrm{co}}$ (Sigurdsson et al., 2000). Para el CEM los parámetros morfométricos mencionados, como $\mathrm{A}_{\text {со }} / \mathrm{D}_{\text {со }}$ y $\mathrm{D}_{\mathrm{cr}} / \mathrm{D}_{\text {со }}$, tienen valores de 0,18 y 0,40 , respectivamente.

Wood (1980) concluye que la relación $\mathrm{A}_{\text {co }} / \mathrm{D}_{\text {co }}$ y el ángulo de inclinación de los flancos disminuyen en función de la degradación del cono por procesos erosivos.

En los conos más viejos, los bajos valores de $\mathrm{H}_{\mathrm{co}} / \mathrm{W}_{\mathrm{co}}$ (relación $\mathrm{A}_{\text {co }} / \mathrm{D}_{\mathrm{co}}$ ) indican una tasa de degradación continua a lo largo del tiempo, reflejando una influencia mayor en la erosión progresiva con respecto a la causada por eventos climáticos extremos (Favalli et al., 2009). Con respecto a la importancia de la relación $H_{c o}$ ' $\mathrm{W}_{\text {co }}$ aplicada en este tipo de escenarios, es importante resaltar que es una medida de estabilidad morfológica, que depende no solo de los factores relacionados anteriormente, sino también de los procesos evolutivos que caracterizan a un cono volcánico (e.g Paricutín, México, Wood 1980). Los modos de degradación de los conos parecen ser similares para todos los conos de escoria en el mundo y son muy influenciados por factores del estado del tiempo como lluvia, el clima en general, y las tasas de cementación (Sigurdsson et al., 2000); pero hay otros factores que inciden en la tasa de degradación como temperaturas altas, el grado de consolidación de los materiales que conforman la estructura volcánica y su composición mineral (Wood, 1980). 


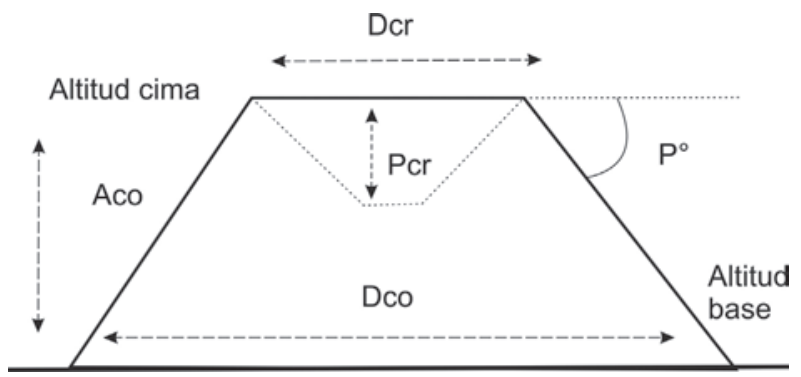

FIGURA 3. Esquema ilustrando los parámetros morfológicos de interés en un cono de escorias. $D_{c r}=$ Diámetro del cráter; $D_{c o}$ = Diámetro de la base del cono; $A_{c o}=$ altura del cono; $P_{c r}=$ profundidad del cráter; $P^{\circ}=$ Pendiente máxima. Tomado de Becerra y Doniz (2008).

\section{Parámetros morfométricos en el CEM}

Se realizó el procesamiento de imágenes de relieve sombreado y se construyó un DEM para crear un mapa de sombras y uno de curvas de nivel con intervalos de contorno de $5 \mathrm{~m}$. Posteriormente se obtuvieron los parámetros morfométricos: $\mathrm{A}_{\mathrm{co}}, \mathrm{D}_{\mathrm{co}}, \mathrm{D}_{\mathrm{cr}}, \mathrm{V}, \mathrm{P}_{\mathrm{cr}} \mathrm{y} \mathrm{P}^{\circ}$, y se calcularon las diferentes relaciones morfométricas: $\mathrm{A}_{\mathrm{co}} /$ $\mathrm{D}_{\mathrm{co}}, \mathrm{D}_{\mathrm{cr}} / \mathrm{D}_{\mathrm{co}}, \mathrm{DM}_{\mathrm{cr}} / \mathrm{dm}_{\mathrm{cr}} \mathrm{y} \mathrm{DM}_{\mathrm{co}} / \mathrm{dm}_{\mathrm{co}}$. La morfometría del CEM fue cuantificada en ArcGIS mediante la delineación manual de los bordes de la base del cono y del cráter (con base en las curvas de nivel) (FIGURA 4). El valor del diámetro de la base del cono se calculó con promedio de cinco distancias debido a la elongación NE-SW del cono y el diámetro del cráter se estimó a partir de un promedio de tres longitudes (FIGURA 4, TABLA 1).
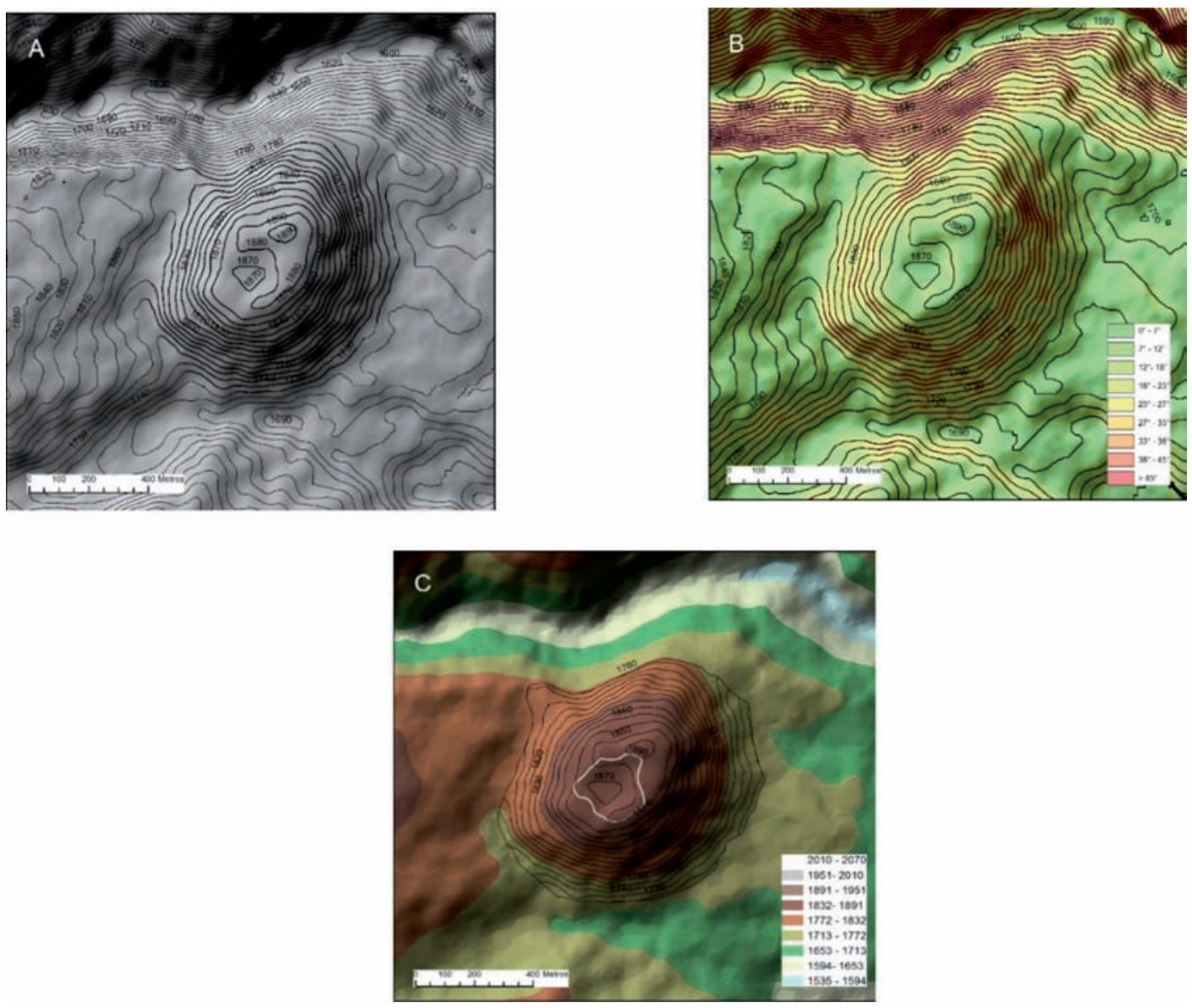

FIGURA 4. Imágenes usadas para la morfometría y morfología del CEM. A. Contornos de la estructura sobre modelo de sombras. B. Contornos sobre mapa de pendientes. C. Contornos sobre mapa de alturas. 
TABLA 1. Dimensiones para diámetro del cono y diámetro del cráter del CEM.

\begin{tabular}{cc}
\hline Diámetro cono $(\mathbf{m})$ & Diámetro cráter $(\mathbf{m})$ \\
\hline 992,91 & 271,23 \\
992,78 & 182,46 \\
823,77 & 176,52 \\
760,85 & - \\
491,31 & - \\
$\overline{\mathbf{x}}=\mathbf{8 1 2 , 3}$ & $\overline{\mathbf{x}}=\mathbf{2 1 0 , 1}$ \\
Mediana $=\mathbf{8 2 3 , 7 7}$ & Mediana $=\mathbf{1 8 2 , 4 6}$ \\
\hline
\end{tabular}

TABLA 2. Parámetros morfométricos del CEM.

\begin{tabular}{cc}
\hline Parámetros y relaciones & Valor en el CEM \\
\hline Altura cono $\left(A_{c o}\right)$ & $126 \mathrm{~m}$ \\
Diámetro cono $\left(D_{c o}\right)$ & $812,3 \mathrm{~m}$ \\
Diámetro cráter $\left(D_{c r}\right)$ & $210,1 \mathrm{~m}$ \\
Profundidad cráter $\left(P_{c r}\right)$ & $15 \mathrm{~m}$ \\
Radio del cono $\left(R_{c o}\right)$ & $406,2 \mathrm{~m}$ \\
Radio del cráter $\left(R_{c r}\right)$ & $105,05 \mathrm{~m}$ \\
Volumen $(V)$ & $23 \times 10^{6} \mathrm{~m}^{3}\left(0,023 \mathrm{~km}^{3}\right)$ \\
Pendiente máxima & $39,6^{\circ}$ \\
Elongación cono & 1,15 \\
Elongación cráter & 1,15 \\
Índice $A_{c o} / D_{c o}\left(H_{c o} / W_{c o}\right)$ & $0,15-0,16^{*}$ \\
Índice $D_{c r} / D_{c o}\left(D_{c r} / W_{c o}\right)$ & $0,22-0,26^{*}$ \\
\hline
\end{tabular}

* El límite inferior se calculó usando la mediana, mientras que el límite superior se calculó usando la media.
Para calcular la altura media del cono $\left(A_{c o}\right)$, se determinó la elevación media de la base del cono y del borde del cráter y se calculó la media aritmética de la elevación de todos los píxeles del DEM localizados en el borde del cono o del cráter, respectivamente (Kervyn et al., 2012), utilizando el mapa de curvas de nivel.

Se determinaron los radios de la base y del cráter para estimar el volumen (V) de la estructura, a partir de la fórmula para un cono truncado (Ecuación 1). Los parámetros y relaciones morfométricas así calculados para el CEM se resumen en la TABLA 2.

$$
V=\pi\left(R c o^{2}+R c r^{2}+((\mathrm{Rco}) \times(\mathrm{Rcr})) \times\left(\frac{A c o}{3}\right)\right.
$$

Donde $\mathrm{R}_{\text {co }}$ es el Radio del cono; $\mathrm{R}_{\text {cr }}$ es el Radio del cráter y $\mathrm{A}_{\text {со }}$ es la Altura del cono.

\section{Estratigrafía}

En la TABLA 3, se resumen los rasgos principales observados y medidos en las diferentes capas de cada paquete estratigráfico identificado en la sección tipo (FIGURA 2), los cuales fueron ilustrados en la FIGURA 5. El orden ascendente en las capas indica la numeración iniciando en base y terminando al techo en cada paquete.

TABLA 3. Características de los niveles de piroclastos en los paquetes estratigráficos de la "Cantera El Morro".

\begin{tabular}{|c|c|c|c|c|c|c|c|}
\hline Paquete & Nivel & Espesor (m) & Estructura & Tamaño de clastos & wt. $\%$ & $\begin{array}{l}\text { Tipo de } \\
\text { clasto }\end{array}$ & Forma \\
\hline \multirow{10}{*}{ P-01 } & 1 & 1,25 & Gradación inversa múltiple & $\begin{array}{c}\text { Bomba fina } \\
\text { Lapilli grueso } \\
\text { Lapilli medio }\end{array}$ & $\begin{array}{l}40 \\
16 \\
44 \\
\end{array}$ & Escorias & Subangular \\
\hline & & & & Bomba fina & 35 & & \\
\hline & 2 & 1,15 & Gradación inversa & Lapilli grueso & 52 & Escorias & Angular \\
\hline & & & & Lapilli fino & 13 & & \\
\hline & 3 & 0,75 & Gradación normal & $\begin{array}{c}\text { Ceniza gruesa } \\
\text { Lapilli grueso } \\
\text { Bomba fina }\end{array}$ & $\begin{array}{c}8 \\
66 \\
26 \\
\end{array}$ & Escorias & Subangular \\
\hline & 4 & 0,30 & Gradación normal & $\begin{array}{l}\text { Lapilli grueso } \\
\text { Bomba fina }\end{array}$ & $\begin{array}{l}33 \\
67\end{array}$ & Escorias & Angular \\
\hline & 5 & 0,80 & Gradación normal & $\begin{array}{c}\text { Ceniza gruesa } \\
\text { Lapilli grueso } \\
\text { Bomba fina }\end{array}$ & $\begin{array}{l}12 \\
63 \\
25 \\
\end{array}$ & Escorias & Subangular \\
\hline & 6 & 1,35 & Gradación normal & $\begin{array}{c}\text { Ceniza gruesa } \\
\text { Lapilli grueso } \\
\text { Lapilli medio } \\
\text { Bomba fina }\end{array}$ & $\begin{array}{c}4 \\
15 \\
29 \\
52 \\
\end{array}$ & Escorias & Subangular \\
\hline & 7 & 1,25 & Gradación inversa & $\begin{array}{l}\text { Lapilli grueso } \\
\text { Lapilli fino }\end{array}$ & $\begin{array}{l}75 \\
25 \\
\end{array}$ & Escorias & Angular \\
\hline & 8 & 0,50 & Gradación normal & $\begin{array}{c}\text { Ceniza gruesa } \\
\text { Lapilli grueso } \\
\text { Bomba fina }\end{array}$ & $\begin{array}{c}9 \\
73 \\
18 \\
\end{array}$ & Escorias & Subangular \\
\hline \multirow[b]{2}{*}{ P-02 } & $\begin{array}{c}9 * \\
\text { Saprolito }\end{array}$ & 0,40 & & & & & \\
\hline & $10 * *$ & 1,35 & $\begin{array}{c}\text { Gradación normal (base) } \\
\text { Inversa (techo) }\end{array}$ & $\begin{array}{l}\text { Ceniza gruesa } \\
\text { Lapilli fino } \\
\text { Lapilli medio } \\
\text { Lapilli grueso } \\
\text { Bomba fina }\end{array}$ & $\begin{array}{c}3 \\
1 \\
24 \\
40 \\
32 \\
\end{array}$ & Escorias & Subangular \\
\hline
\end{tabular}


Continuación TABLA 3

\begin{tabular}{|c|c|c|c|c|c|c|c|}
\hline Paquete & Nivel & Espesor (m) & Estructura & Tamaño de clastos & wt. \% & $\begin{array}{c}\text { Tipo de } \\
\text { clasto }\end{array}$ & Forma \\
\hline \multirow{6}{*}{ P-02 } & \multirow{3}{*}{11} & \multirow{3}{*}{0,55} & \multirow{3}{*}{ Gradación normal } & Ceniza gruesa & 4 & \multirow{3}{*}{ Escorias } & \multirow{3}{*}{ Subangular } \\
\hline & & & & Lapilli fino & 7 & & \\
\hline & & & & Bomba fina & 89 & & \\
\hline & \multirow{3}{*}{12} & \multirow{3}{*}{0,50} & \multirow{3}{*}{ Gradación normal } & Lapilli fino & 17 & \multirow{3}{*}{ Escorias } & \multirow{3}{*}{ Subangular } \\
\hline & & & & Lapilli medio & 50 & & \\
\hline & & & & Lapilli grueso & 33 & & \\
\hline \multirow{4}{*}{ P-03 } & 13 & 0,35 & Gradación normal & $\begin{array}{l}\text { Lapilli medio } \\
\text { Ceniza media }\end{array}$ & $\begin{array}{l}86 \\
14\end{array}$ & Escorias $^{+}$ & Subangular \\
\hline & 14 & 0,75 & Gradación normal & $\begin{array}{l}\text { Ceniza gruesa } \\
\text { Lapilli fino } \\
\text { Lapilli medio }\end{array}$ & $\begin{array}{c}7 \\
40 \\
53 \\
\end{array}$ & Escorias & $\begin{array}{c}\text { Subredondeada a } \\
\text { Subangular }\end{array}$ \\
\hline & 15 & 1,30 & Gradación inversa & $\begin{array}{l}\text { Lapilli fino } \\
\text { Bomba fina } \\
\text { Bomba media }\end{array}$ & $\begin{array}{l}38 \\
24 \\
38\end{array}$ & Escorias & $\begin{array}{l}\text { Subangular a } \\
\text { angular }\end{array}$ \\
\hline & $16^{++}$ & 1,20 & Gradación inversa múltiple & Lapilli medio & 67 & Escorias & Subangular \\
\hline
\end{tabular}

\section{Análisis de materia orgánica}

Los análisis químicos realizados al material en la base del paquete P-02 (ver TABLA 3), muestran que el material presenta $\mathrm{pH}$ alcalino, este alto contenido de bases indica condiciones climáticas secas. El bajo porcentaje de carbón orgánico indica que es un suelo de desarrollo incipiente, conserva las estructuras de la roca original, pero presenta alto grado de meteorización, por lo que es considerado como saprolito. Las altas concentraciones de Ca sugieren proveniencia de ceniza volcánica rica en plagioclasa cálcica. El material posee alta capacidad de intercambio catiónico, propiedad directamente proporcional a la cantidad de arcillas, las cuales son de tipo bentonita cálcica. La textura es francoarenosa con alta proporción de arcilla y limo (TABLA 4).

\section{Columnas estratigráficas paquetes CEM}
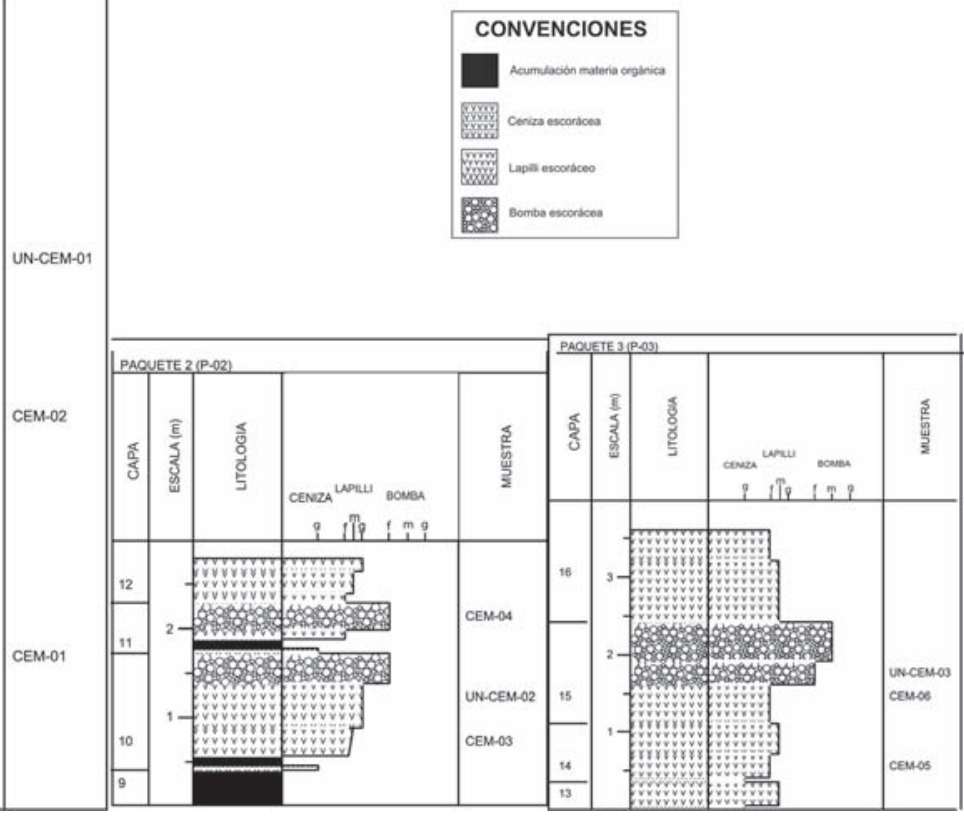

FIGURA 5. Columnas estratigráficas. Los niveles de cada columna corresponden a aquellos de la TABLA 3. 
TABLA4. Resultados de análisis químicos: $\mathrm{pH}, \mathrm{CO}$, P, bases (K, Ca, Mg, Na), acidez de cambio, CICE (Capacidad de Intercambio Catiónico Efectiva) y textura para el nivel 9 en el paquete 2.

\begin{tabular}{|c|c|c|c|c|c|c|c|c|c|c|c|c|c|}
\hline pH & $\mathrm{CO}$ & $\mathbf{N}$ & $\mathrm{Ca}$ & $\mathbf{K}$ & Mg & $\mathrm{Na}$ & AI & CICE & $\mathbf{P}$ & Ar & $\mathbf{L}$ & A & Textura \\
\hline & $\%$ & $\%$ & $\begin{array}{c}\text { meq / } \\
100 \mathrm{~g}\end{array}$ & $\begin{array}{c}\text { meq / } \\
100 \mathrm{~g}\end{array}$ & $\begin{array}{c}\text { meq / } \\
100 \mathrm{~g}\end{array}$ & $\begin{array}{c}\text { meq / } \\
100 \mathrm{~g}\end{array}$ & $\begin{array}{c}\text { meq / } \\
100 \mathrm{~g}\end{array}$ & $\begin{array}{c}\text { meq / } \\
100 \mathrm{~g}\end{array}$ & $\begin{array}{c}\mathrm{mg} / \\
\mathrm{kg}\end{array}$ & $\%$ & $\%$ & $\%$ & \\
\hline 7,5 & 0,48 & 0,04 & 4,04 & 0,56 & 6,90 & 0,56 & 0,00 & 12,1 & $>116$ & 18 & 24 & 58 & FA \\
\hline
\end{tabular}

CO: Carbono orgánico oxidable. N: Nitrógeno total. Ca, K, Mg, Na: Bases intercambiables. AI: Acidez intercambiable. CICE: Capacidad de intercambio catiónico efectiva. P: Fósforo disponible. Ar: Arcilla. L: Limo. A: Arena. FA: Francoarenosa.

\section{Petrografía}

\section{UN-CEM-01}

Esta muestra, seleccionada de los clastos colectados en el paquete P-01, es hipocristalina, con textura porfirítica, fenocristales (23 vol.\%) de $1 \mathrm{~mm}$ a $11 \mathrm{~mm}$ y matriz $(58,4 \%)$ con cristales de tamaños menores a $1 \mathrm{~mm}$. La textura general es inequigranular, y las texturas específicas corresponden a vesicular e intergranular. La masa fundamental está compuesta esencialmente por cristales euhedrales de plagioclasa de composición $A n_{80}-\mathrm{An}_{96}$ según su ángulo de extinción

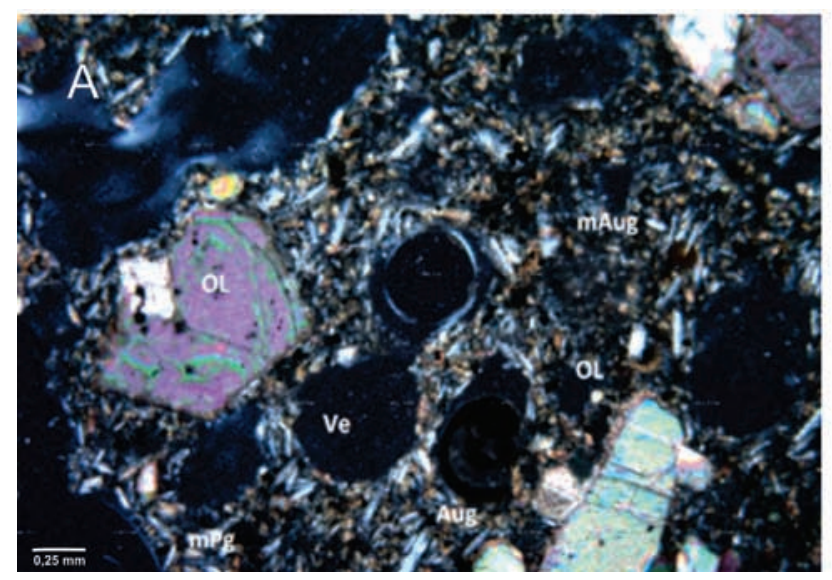

con maclas polisintéticas, además de cristales de olivino y clinopiroxeno. Los fenocristales son principalmente de olivino $(74,4 \%)$ con formas subhedrales a anhedrales y algunos presentan un borde de minerales secundarios de óxidos de hierro, inclusiones de minerales opacos y se encuentran corroídos. Otros minerales son fenocristales euhedrales a subhedrales de augita (19,2\%), plagioclasa $(3,4 \%)$, opácos $(2,6 \%)$ y apatito $(0,4 \%)$. Para la clasificación de la roca se normalizaron los valores de las plagioclasas. De acuerdo con las plagioclasas y el índice de color melanocrático (70\%), la roca puede clasificarse como un basalto (ver FIGURA 6).

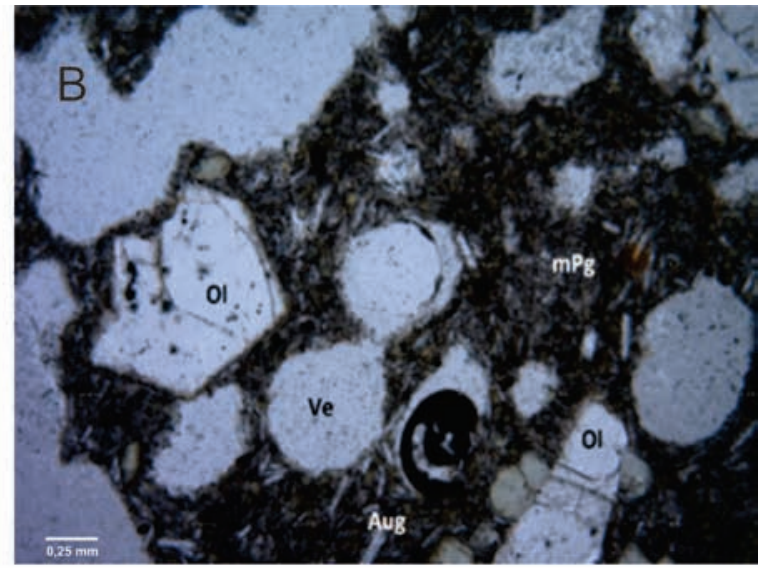

FIGURA 6. Fotomicrografías de sección delgada de la muestra UN-CEM-01. Basalto con fenocristales de olivino (Ol) y Augita (Aug), en una matriz con vesículas (Ve) rica en cristales de plagioclasa (mPg) y cristales de augita (mAug). A. Nicoles cruzados. B. Nicoles paralelos.

\section{UN-CEM-02}

Esta muestra, seleccionada de los clastos colectados en el paquete P-02, es hipocristalina, con fenocristales (39 vol.\%) de $1 \mathrm{~mm}$ a $6 \mathrm{~mm}$ y masa fundamental (57 vol.\%) con cristales de tamaños menores a $0,7 \mathrm{~mm}$. La textura general es inequigranular seriada y texturas específicas intergranular y vesicular. La masa fundamental está compuesta por cristales euhedrales de plagioclasa de composición $\mathrm{An}_{82}-\mathrm{An}_{95}$ según su ángulo de extinción con macla polisintética, además de cristales de olivino y clinopiroxeno. Los fenocristales son olivinos subhedrales a anhedrales (80,8\%) con bahías de corrosión. Otros fenocristales incluyen: augita subhedral (12,6\%), opácos (4\%), plagioclasa (2,4\%), y apatito $(0,2 \%)$.

De acuerdo con las plagioclasas y el índice de color melanocrático (65\%), la roca puede clasificarse como un basalto (FIGURA 7). 

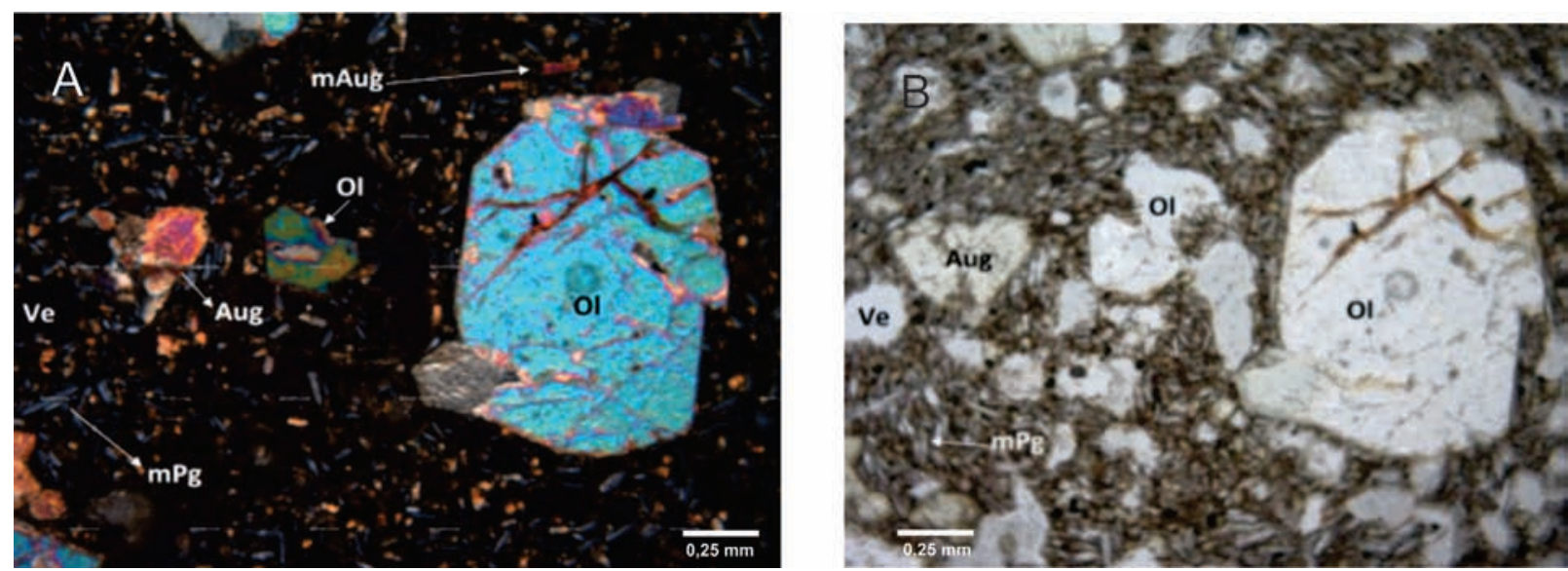

FIGURA 7. Fotomicrografías de secciones delgadas de la muestra UN-CEM-02. Basalto con fenocristales de olivino (Ol) y augita (Aug) en una masa fundamental rica en cristales de plagioclasa (mPg) y cristales de augita (mAug), con textura escoriácea (Vesiculas: Ve). El olivino presenta oxidación al interior de las fracturas irregulares. A. Nicoles cruzados. B. Nicoles paralelos.

\section{UN-CEM-03}

Esta muestra, seleccionada de los clastos colectados en el paquete $\mathrm{P}-03$, posee textura porfirítica, hipocristalina, con fenocristales (27 vol.\%) de $1 \mathrm{~mm}$ a $8 \mathrm{~mm}$ y masa fundamental (44 vol.\%) con cristales de tamaños menores a $0,4 \mathrm{~mm}$. La textura general es inequigranular seriada con texturas específicas vesicular e intergranular. La masa fundamental está compuesta por cristales euhedrales de plagioclasa de composición $\mathrm{An}_{91}-\mathrm{An}_{98}$ según su ángulo de extinción, con macla polisintética, y por cristales de olivino y clinopiroxeno. Los fenocristales subhedrales a anhedrales de olivino (66,4\%) se encuentran corroídos. Otros minerales son augita subhedral (26,8\%), opácos (5\%) y plagioclasa (1,8\%). De acuerdo con las plagioclasas y el índice de color melanocrático (70\%), la muestra corresponde modalmente a un basalto (FIGURA 8).
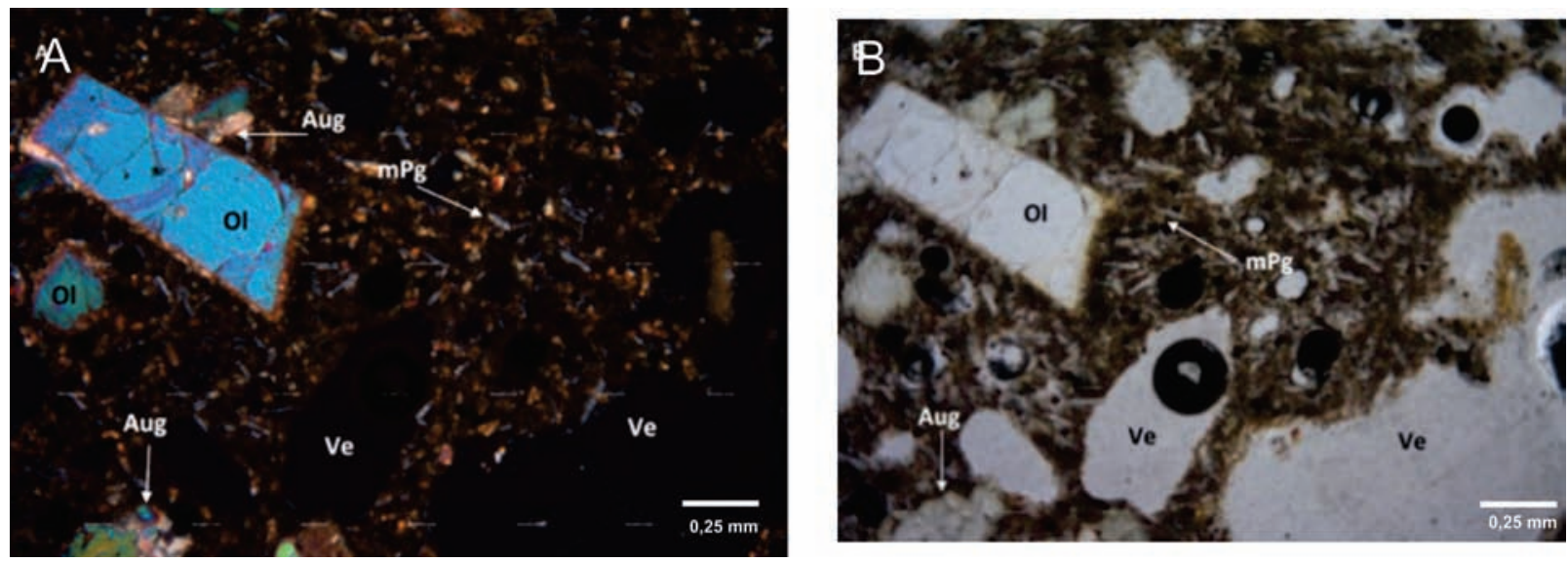

FIGURA 8. Fotomicrografías de secciones delgadas de la muestra UN-CEM-03. Basalto con fenocristales de olivino (Ol) y augita (Aug) en una masa fundamental rica en cristales de plagioclasa (mPg), con mucha vesicularidad (Ve). El olivino se encuentra alterado en los bordes. A. Nicoles cruzados. B. Nicoles paralelos.

\section{Geoquímica}

\section{Composición de elementos mayores y traza}

El contenido de sílice en las seis muestras colectadas en el CEM varía entre 47,69 wt.\% y 49,11 wt.\%, mientras que el contenido de álcalis total $\left(\mathrm{Na}_{2} \mathrm{O}+\mathrm{K}_{2} \mathrm{O}\right)$ varía entre 3,62 wt.\% y 5,56 wt.\%, por lo que puede corroborarse la composición basáltica y afinidad predominantemente alcalina de las muestras (FIGURA 9). Los valores de
$\mathrm{Fe}_{2} \mathrm{O}_{3}$ varían entre 9,84 wt.\% y 12,41 wt.\%. Se observan altos contenido de $\mathrm{Al}_{2} \mathrm{O}_{3}$, que están en un rango de 15,49 wt.\% a 17,55 wt.\% en peso, el $\mathrm{CaO}$ se encuentra entre 9,43 wt.\% - 10,37 wt.\% y el MgO entre 6,13 wt.\% 8,09 wt.\%. El contenido de $\mathrm{MnO}$ se encuentra entre 0,16 wt.\% y 0,19 wt. $\%$ y el $\mathrm{TiO}_{2}$ aparece en concentraciones bajas, generalmente inferiores a 1,4 wt.\%. Los datos de composición de roca total (elementos mayores y traza) reportados se muestran en la TABLA 5. 
TABLA 5. Datos normalizados de elementos mayores (wt \%) y traza (ppm) en las muestras del flanco W del CEM.

\begin{tabular}{|c|c|c|c|c|c|c|}
\hline Elemento & CEM-01 & CEM-02 & CEM-03 & CEM-04 & CEM-05 & CEM-06 \\
\hline $\mathrm{SiO}_{2}$ & 47,69 & 47,89 & 48,66 & 48,81 & 49,09 & 49,11 \\
\hline $\mathrm{Al}_{2} \mathrm{O}_{3}$ & 15,49 & 15,58 & 17,55 & 16,25 & 15,93 & 16 \\
\hline $\mathrm{Fe}_{2} \mathrm{O}_{3}$ & 11,44 & 11,50 & 12,41 & 10,69 & 9,84 & 9,89 \\
\hline $\mathrm{CaO}$ & 10,37 & 10,23 & 9,43 & 9,90 & 9,47 & 9,65 \\
\hline $\mathrm{MgO}$ & 7,65 & 7,46 & 6,13 & 7,42 & 8,09 & 7,76 \\
\hline $\mathrm{Na}_{2} \mathrm{O}$ & 3,92 & 3,97 & 2,71 & 3,88 & 4,52 & 4,43 \\
\hline $\mathrm{TiO}_{2}$ & 1,40 & 1,38 & 1,42 & 1,28 & 1,19 & 1,20 \\
\hline $\mathrm{K}_{2} \mathrm{O}$ & 1,20 & 1,16 & 0,91 & 1,01 & 1,04 & 1,09 \\
\hline $\mathrm{P}_{2} \mathrm{O}_{5}$ & 0,68 & 0,64 & 0,58 & 0,59 & 0,68 & 0,70 \\
\hline $\mathrm{MnO}$ & 0,16 & 0,18 & 0,19 & 0,16 & 0,15 & 0,15 \\
\hline $\mathrm{Sr}$ & 1380 & 1410 & 1350 & 1300 & 1160 & 1200 \\
\hline $\mathrm{Ba}$ & 1200 & 1420 & 1440 & 1580 & 1170 & 1200 \\
\hline $\mathrm{Cl}$ & 990 & 840 & 670 & 830 & 540 & 710 \\
\hline $\mathrm{SO}_{3}$ & 530 & 830 & 700 & 490 & 100 & 140 \\
\hline $\mathrm{Cr}$ & 530 & 460 & 570 & 480 & 490 & 510 \\
\hline V & 270 & 300 & 330 & 290 & 370 & 280 \\
\hline $\mathrm{Ni}$ & 210 & 240 & 250 & 170 & 160 & 110 \\
\hline Co & 190 & 260 & LLD & 140 & 200 & 190 \\
\hline $\mathrm{Cu}$ & 190 & 150 & 120 & 110 & 100 & 110 \\
\hline $\mathrm{Zn}$ & 130 & 110 & 140 & 90 & 90 & 90 \\
\hline $\mathrm{Rb}$ & 40 & 20 & 30 & 20 & 20 & 20 \\
\hline $\mathrm{Y}$ & 30 & 30 & 30 & 20 & 20 & 20 \\
\hline $\mathrm{Nb}$ & 30 & 30 & LLD* & 20 & 20 & 20 \\
\hline
\end{tabular}

\section{Discriminación tectónica}

Se realizaron diagramas Harker para proyectar el wt\% de $\mathrm{SiO}_{2}$ sobre el eje $\mathrm{X}$ contra los restantes óxidos en el eje Y, de acuerdo a Harker (1909), quien propuso que de esta manera se puede mostrar la intensidad en la evolución magmática. Para la discriminación tectónica se utilizó el diagrama propuesto por Mullen (1983) el cual es basado en elementos menores para basaltos y andesitas basálticas cuya concentración de $\mathrm{SiO}_{2}$ está en el rango 45 y 54 wt\%. El diagrama de variación TAS $\left(\mathrm{Na}_{2} \mathrm{O}+\mathrm{K}_{2} \mathrm{O}\right)$ vs $\mathrm{SiO}_{2}$ indica que las muestras CEM-01 a CEM-06, excepto la muestra CEM-03, corresponden a muestras de la serie alcalina, y se sub-clasifican como traqui-basaltos (FIGURA 9).

Por medio del diagrama de la FIGURA 10, el magma se clasifica de la serie alcalina (álcali-calcio $<51 \%$ ), ya que existe un enriquecimiento variable de Fe. Siguiendo el diagrama de discriminación tectónica de Mullen (1983), (FIGURA 11), se encontró que las muestras están dentro del campo CAB (continental arc basalts), lo que indica que están asociadas a ambiente de subducción. 


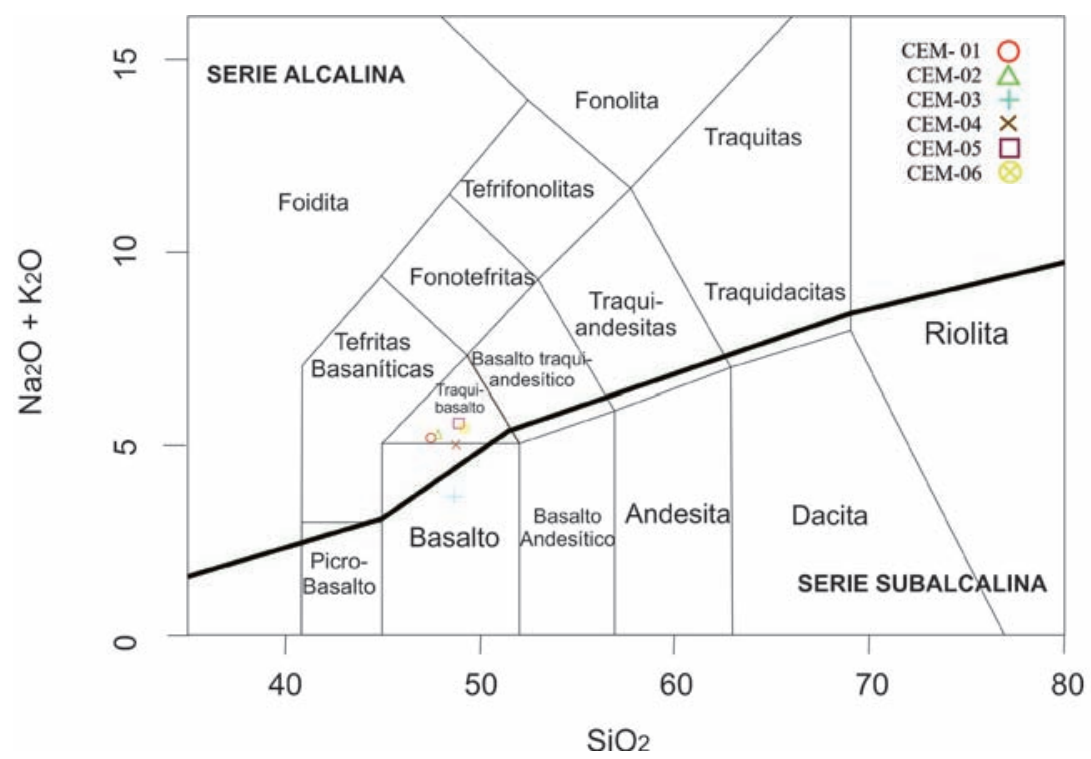

FIGURA 9. Diagrama de clasificación geoquímica TAS $\left(\mathrm{Na}_{2} \mathrm{O}+\mathrm{K}_{2} \mathrm{O}\right)$ vs $\mathrm{SiO}_{2}$ (Le Maitre et al., 2002).
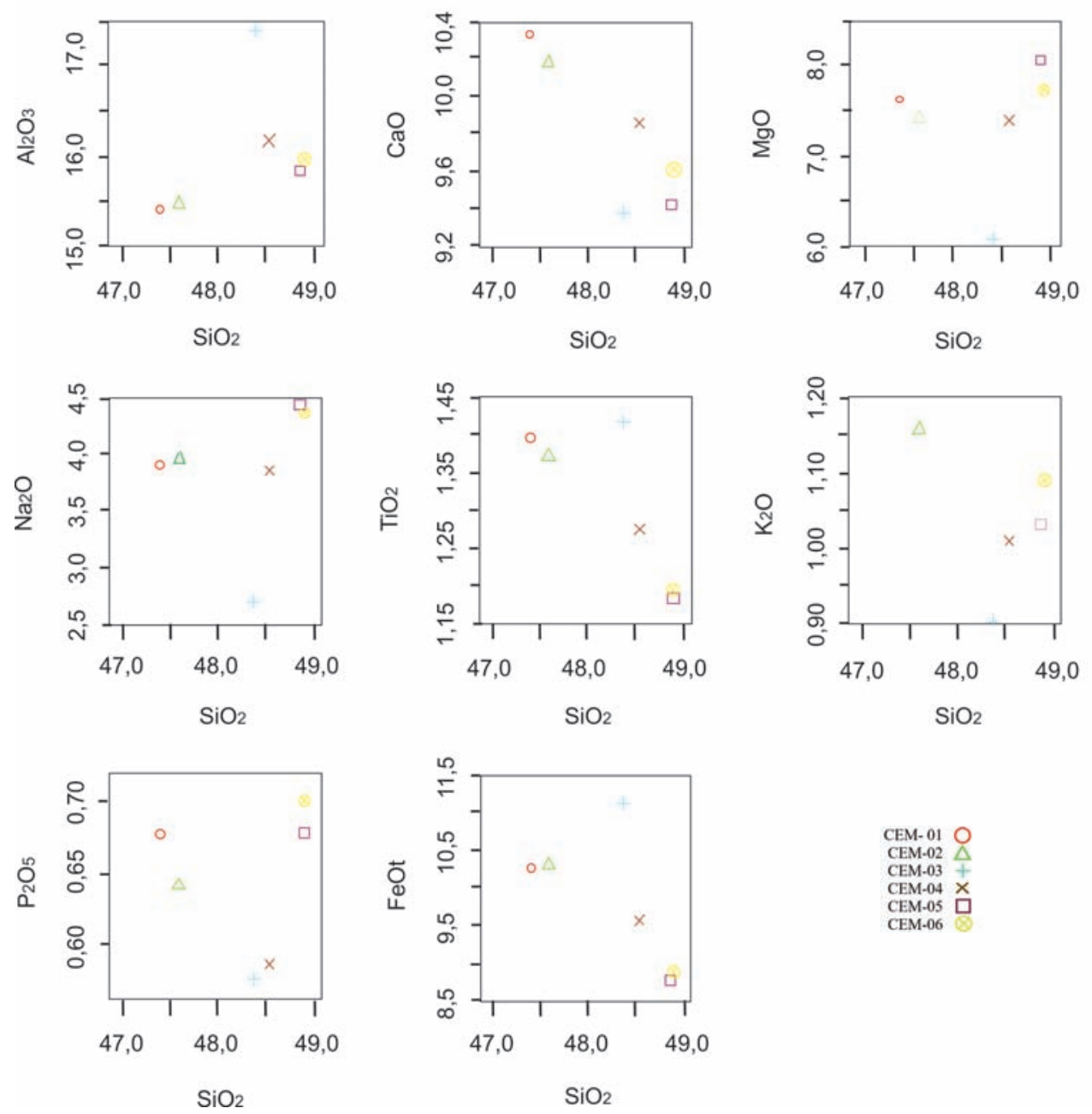

FIGURA 10. Diagramas de clasificación (Harker, 1909). 


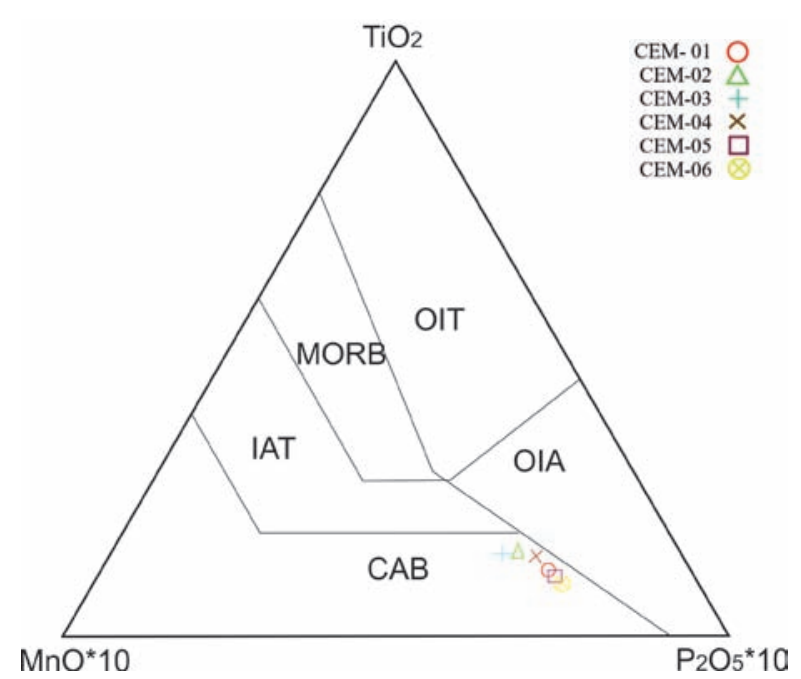

FIGURA 11. $\mathrm{MnO}-\mathrm{TiO}_{2}-\mathrm{P}_{2} \mathrm{O}_{5}$ para basaltos y andesitas basálticas según Mullen (1983).

\section{Norma CIPW}

Las muestras analizadas (exceptuando CEM-03) indican olivino normativo (Ol) entre 7,61 y 9,316 y nefelina normativa $(\mathrm{Ne})$ entre 1,473 y 2,336, es decir, se trata de rocas subsaturadas en $\mathrm{SiO}_{2}$. La muestra "anómala" CEM-03 presenta cuarzo normativo (Q) 3,832 e hyperstena normativa (Hy) 13,1, típicos de rocas sobresaturadas en $\mathrm{SiO}_{2}$ (TABLA 6).

TABLA 6. Norma CIPW para las rocas del flanco W del CEM.

\begin{tabular}{ccccccc}
\hline Elemento & CEM-01 & CEM-02 & CEM-03 & CEM-04 & CEM-05 & CEM-06 \\
\hline Q & 0 & 0 & 3,832 & 0 & 0 & 0 \\
Or & 7,05 & 6,832 & 5,342 & 5,963 & 6,099 & 6,436 \\
$\mathrm{Ab}$ & 29,633 & 30,654 & 22,831 & 32,628 & 33,758 & 33,6 \\
$\mathrm{An}$ & 20,984 & 21,131 & 32,839 & 23,805 & 20,038 & 20,453 \\
$\mathrm{Ne}$ & 1,834 & 1,473 & 0 & 0 & 2,336 & 1,995 \\
$\mathrm{Di}$ & 16,758 & 16,415 & 4,479 & 13,551 & 14,597 & 14,862 \\
$\mathrm{Hy}$ & 0 & 0 & 13,1 & 0,011 & 0 & 0 \\
Ol & 7,832 & 7,61 & 0 & 8,475 & 9,316 & 8,663 \\
$\mathrm{Il}$ & 0,334 & 0,387 & 0,406 & 0,338 & 0,325 & 0,327 \\
$\mathrm{Hm}$ & 11,374 & 11,429 & 12,348 & 10,63 & 9,795 & 9,851 \\
$\mathrm{Tn}$ & 0 & 0 & 2,956 & 2,696 & 0 & 0 \\
Pf & 2,074 & 1,986 & 0 & 0 & 1,73 & 1,738 \\
$\mathrm{Ap}$ & 1,601 & 1,518 & 1,364 & 1,388 & 1,606 & 1,66 \\
\hline
\end{tabular}

\section{DISCUSIÓN}

El CEM fue estudiado a partir de datos recolectados en campo en la mejor exposición de sus depósitos disponible hasta el momento (“Cantera El Morro") junto con observaciones adicionales en afloramientos menores cercanos. En principio se trata de un centro eruptivo basáltico con características de estructura volcánica primaria y específicamente puede llamarse un cono de escoria ( $c f$. De Silva y Lindsay, 2015).

En relación con la morfología y morfometría, se realizaron medidas de dimensiones y relaciones entre dimensiones para el CEM (TABLAS 1 y 2). Se ha sugerido que, por ejemplo, las relaciónes $\mathrm{A}_{\text {co }} / \mathrm{D}_{\text {со }}\left(\mathrm{H}_{\mathrm{co}} /\right.$ $\mathrm{W}_{\mathrm{co}}$, Wood, 1980) $=1,8, \mathrm{y} \mathrm{D}_{\mathrm{cr}} / \mathrm{D}_{\mathrm{co}}\left(\mathrm{D}_{\mathrm{cr}} / \mathrm{W}_{\mathrm{co}}\right.$, Porter, 1972) 
$=0,4$ son típicas de conos formados por clastos tamaño lapilli-bomba, depositados a través de proyectiles balísticos. Por otra parte, Settle (1979) sugiere que (A $/$ $\left.\mathrm{D}_{\text {co }}\right) \max =0,2$ representa conos recientes de morfología simple. En el caso del CEM $\mathrm{A}_{\text {co }} / \mathrm{D}_{\text {co }}=0,15-0,16$ y $\mathrm{D}_{\mathrm{cr}} /$ $\mathrm{D}_{\text {co }}=0,22-0,26$, valores suficientemente cercanos a los valores de referencia mencionados y que en conjunto con las observaciones de campo y los datos de la TABLA 3 indican que el CEM habría sido formado por caídas piroclásticas durante erupciones estrombolianas. La actividad eruptiva durante la formación del CEM habría sido de carácter rítmico en intensidad, evidenciado en el depósito en la alternancia entre gradaciones inversa y normal. En general durante erupciones estrombolianas típicas los clastos de mayor tamaño no son expulsados muy lejos del cráter y tienden a caer balísticamente en cercanías a éste.

Desde su conformación, los procesos erosivos, que tienden a reducir la altura media del cono y aumentar el diámetro medio de su base, no han sido dominantes. Fornaciai et al. (2012) sugieren que los índices $\mathrm{A}_{\mathrm{co}} / \mathrm{D}_{\mathrm{co}}=$ 0,15 y $\mathrm{D}_{\mathrm{cr}} / \mathrm{D}_{\mathrm{co}}=0,30$ estarían relacionados al ambiente geodinámico (los conos de zonas de subducción son de mayor tamaño que los conos intraplacas) y a la forma prevalente del cono. Desde esta perspectiva, el CEM es un cono de ambiente de subducción $\mathrm{A}_{\text {co }} / \mathrm{D}_{\text {co }}=0,15-$ 0,16 y $_{\text {cr }} / \mathrm{D}_{\text {со }}=0,22-0,26$, de nuevo, valores similares a los de referencia.

Los paquetes estratigráficos, informalmente denominados en este trabajo, ocasionalmente se encuentran separados por dos acumulaciones de materia orgánica, definidos como saprolitos (TABLA 4), las cuales indicarían, que a pesar de ser un volcán monogenético, su evolución incluyó algunos breves reposos donde los clastos sufrieron saprolitización.

En lo referente a petrografía, las tres muestras analizadas (una en cada paquete) se clasifican como basalto (Streckeisen, 1979), lo que indica de manera general la composición monótona del CEM. El importante contenido de fenocristales y microcristales en las muestras (FIGURAS 6, 7 y 8) indica que los fenocristales deben haber crecido en un número más pequeño de núcleos, comparados con la alta densidad de nucleación de la matriz fundida. Esto corresponde a un magma profundo que se enfría lentamente en su ambiente. Los bordes de reacción en los olivinos indican condiciones cambiantes probablemente durante ascenso a superficie o durante almacenamiento (López y Bellos, 2006).
Los análisis químicos (TABLA 5) revelan que las muestras CEM-01 a CEM-06 corresponden a traqui basaltos y basaltos (FIGURAS 9 y 10). La clasificación geotectónica señala principalmente afinidad de arco continental (FIGURA 11). La correlación de los elementos mayores con $\mathrm{SiO}_{2}$ (FIGURA 10) sugiere una evolución de la serie por cristalización fraccionada. La distribución de $\mathrm{CaO}$, y de $\mathrm{MgO}$ en las muestras CEM-01 y CEM-02 es coherente con un conjunto de fraccionamiento olivino + clinopiroxeno.

El fraccionamiento de olivino produce un enriquecimiento en $\mathrm{Al}_{2} \mathrm{O}_{3}$, con fraccionamiento de clinopiroxeno hay disminución de $\mathrm{CaO}$ y $\mathrm{TiO}_{2}$ (FIGURA 10). La disminución conjunta de $\mathrm{TiO}_{2}$ y $\mathrm{FeO}$ responde al fraccionamiento de accesorios ferrromagnesianos y el empobrecimiento de los contenidos de $\mathrm{P}_{2} \mathrm{O}_{5}$ es debido a la cristalización del apatito, en 4 de las 6 muestras. El $\mathrm{Na}_{2} \mathrm{O}$ se acumula hasta los términos evolucionados en relación directa a la presencia de minerales máficos alcalinos, pero en este tipo de clastos, los valores presentan dispersión y son muy variables.

La muestra CEM-03 destaca en su composición (FIGURAS 9 y 10), y el análisis de la norma CIPW muestra que es la única que presenta cuarzo normativo de 3,832 wt. \%, y que no tiene olivino normativo. Aunque esto parecería muy extraño, en ocasiones se reportan variaciones composicionales dentro de un mismo volcán o depósito y de igual manera se conocen asociaciones minerales cuarzo-olivinoenstatita texturalmente evidenciadas en fenocristales de olivino con bordes de reacción de enstatita y cuarzo intergranular, que representan equilibrios especiales alcanzados entre algunas fases del fundido magmático durante condiciones cambiantes, especialmente disminución de temperatura (Best, 2002). También, puede ser considerado como un fragmento accesorio, ya que su composición difiere de las otras cinco muestras, y pudo ser un clasto preexistente, involucrado durante la erupción desde el conducto, el edificio volcánico o los depósitos asociados a éste (Murcia et al., 2013).

\section{CONCLUSIONES}

En general, a escala de afloramiento, el CEM, ubicado cerca al municipio La Argentina (Huila), presenta clastos agrupados en tres paquetes de acumulación distinguibles, con granulometría y morfología muy homogénea, adicionalmente fueron observadas y documentadas leves acumulaciones de materia 
orgánica con alto grado de meteorización, indicando breves reposos en su evolución. El edificio es de morfología simple y no muestra haber sido afectado por procesos erosivos, por lo cual se sugiere que la formación del CEM es reciente.

La petrografía y geoquímica de los clastos del CEM indican emisión de un magma de composición traquibasáltica. A partir de las relaciones morfométricas y los diagramas de discriminación del ambiente geotectónico se concluyó que los fragmentos analizados sugieren afinidad con arco continental y su ambiente de formación está asociado a subducción.

\section{AGRADECIMIENTOS}

Los autores agradecen al Departamento de Geociencias, a la Facultad de Ciencias de la Universidad Nacional de Colombia-Sede Bogotá por el apoyo académico. Al profesor Juan Manuel Moreno por guiar hacia la cantera de El Morro, ayudar a la recolección inicial de muestras y motivar a su estudio. Adicionalmente, al señor Oscar Ricardo Lara, quien colaboró en la recolección final de las muestras durante la salida de campo. Los comentarios y revisiones de la Dra. Natalia Pardo (Universidad de los Andes, Colombia) y el Dr. José Marcelo Arnosio (Universidad Nacional de Salta, Argentina) ayudaron a mejorar la calidad del trabajo.

\section{REFERENCIAS}

Becerra, R., y Doniz, J. (2008). Aplicación del análisis morfométrico a los volcanes del extremo suroriental de la Región Volcánica del Campo de Calatrava (Ciudad Real, España). En: J. Benavente, F.J. Gracia (eds.). Trabajos de Geomorfología en España, 2006-2008 (pp. 21-24). Cádiz: SEG.

Best, M.G. (2002). Igneous and metamorphic petrology. 2nd Edition, Willey-Blackwell. New Jersey.

De Silva, S., and Lindsay, J.M. (2015). Primary volcanic landforms. In: H. Sigurdsson, B. Houghton, R.S. McNutt, H. Rymer, J. Stix (eds.). The encyclopedia of volcanoes (pp.279-297). 2nd Edition, Academic Press.

Dixon, L.H. (1953). Reconnaisance geology the Upper Magdalena Valley from Neiva, E. Pitalito. Internat. Petrol (Colombia) Ltda. Bogotá.
Favalli, M., Karátson, D., Mazzarini, F., Pareschi, M.T., and Boschi, E. (2009). Morphometry of scoria cones located on a volcano flank: A case study from Mt. Etna (Italy) based on highresolution LiDAR data. Journal of Volcanology and Geothermal Research, 186(3-4), 320- 330. doi: 10.1016/j.jvolgeores.2009.07.011.

Flores, J.A. (2009). Geología y petrogénesis de los volcanes monogenéticos Pelagatos, Cerro del Agua y Dos Cerros en la Sierra Chichinautzin, al sur de la Ciudad de México. Tesis de Maestría, Universidad Nacional Autónoma de México, México.

Flórez, A. (2003). Colombia: Evolución de sus relieves y modelados. Bogotá: Universidad Nacional de Colombia.

Fornaciai, A., Favalli, M., Karátson, D., Tarquini, S., and Boschi, E. (2012). Morphometry of scoria cones, and their relation to geodynamic setting: A DEM-based analysis. Journal of Volcanology and Geothermal Research, 217-218, 56-72. doi: 10.1016/j.jvolgeores.2011.12.012.

Harker, A. (1909). The natural history of igneous rocks. New York: Hafner.

Hernández, T., y Tello, H. (1978). Estudio geológico de San Agustín (Huila). Boletín Museo de Oro, 2, 50-55.

Janoušek, V., Erban, V., and Farrow, C.M. (2000). GCDkit: Geochemical Data Toolkit (Versión 5.0). Software. http://www.gcdkit.org/download.

JAXA (2011). Advanced Land Observing Satellite, Daichi-2, Daichi, ALOS-2, ALOS. Japan Aerospace Exploration Agency. Consultado el 21 de mayo de 2017. http://www.eorc.jaxa.jp.

Kervyn, M., Ernst, G.G.J., Carracedo, J.C., and Jacobs, P. (2012). Geomorphometric variability of "monogenetic" volcanic cones: Evidence from Mauna Kea, Lanzarote and experimental cones. Geomorphology, 136(1), 59-75. doi: 10.1016/j. geomorph.2011.04.009

Kroonenberg, S., León, L.A., Pastana, J.M., y Pessoa, M.R. (1981). Ignimbritas pliopleistocénicas en el suroeste del Huila, Colombia y su influencia en el desarrollo morfológico. Revista CIAF, 6(1-3), 293-314. 
Le Maitre, R.W., Streckeisen, A., Zanettin, B., Le Bas, M.J., Bonin, P., Bateman, B., Bellieni, G., Dudek, A., Efremova, S., Keller, J., Lameyre, J., Sabine, P.A., Schmid, R., Sørensen, H., y Woolley, A.R. (2002). Igneous Rocks. A Classification and Glossary of Terms. Recommendations of the IUGS Subcommission on the Systematics of Igneous Rocks. Cambridge: Cambridge University Press.

López, J.P., y Bellos, L.I. (2006). Texturas y estructuras de las rocas igneas: Significado petrológico e implicancias en las condiciones de formación de las rocas. INSUGEO, Miscelánea, 15, 7-57.

Marquínez, G., Rodríguez, Y., Terraza, R., y Martínez, M. (2003). Geología de la Plancha 365 Coconuco. Informe Interno, INGEOMINAS, 73 pp.

Montes, N.E. (2001). Actividad Neotectónica del Valle Superior del Magdalena. VII Congreso Colombiano de Geología, Manizales. Colombia.

Mullen, E.D. (1983). $\mathrm{MnO} / \mathrm{TiO}_{2} / \mathrm{P}_{2} \mathrm{O}_{5}$ : a minor element discriminant for basaltic rocks of oceanic environments and its implications for petrogenesis. Earth and Planetary Science Letters, 62(1), 5362. doi: 10.1016/0012-821X(83)90070-5.

Murcia, H.F., Borrero, C.A., Pardo, N., Alvarado, G.E., Arnosio, M., y Scolamacchia, T. (2013). Depósitos volcaniclásticos: Términos y conceptos para una clasificación en español. Revista Geológica de América Central, 48, 15-39. doi: 10.15517/rgac. v0i48.12211.

Núñez, A. (1998). Batolito de Ibagué. Catálogo de las unidades litoestrátigráficas de Colombia. INGEOMINAS, Ibagué, Colombia.

Pérez, Y.A. (2012). Análisis morfométrico, petrográfico y geoquímico del Cono La Guaca, Nariño Colombia. Tesis, Departamento de Geociencias, Universidad Nacional de Colombia, Bogotá, Colombia.

Porter, S.C. (1972). Distribution, morphology, and size frequency of cinder cones on Mauna Kea Volcano, Hawaii. GSA Bulletin, 83(12), 3607-3612. doi:
10.1130/0016-7606(1972)83[3607:DMASFO]2. $0 . \mathrm{CO} ; 2$.

Robertson, K., Flórez, A., y Ceballos, J. (2002). Geomorfología volcánica, actividad reciente y clasificación en Colombia. Cuadernos de Geografía: Revista Colombiana de Geografía, 11(1-2), 37-76.

Samacá, W. (2016). Análisis morfométrico y geomorfológico de la Caldera de Paletará (Cauca), Colombia. Tesis de Maestría, Universidad Nacional de Colombia, Bogotá, Colombia.

Sigurdsson, H., Houghton, B., McNutt, S.R., Rymer, H., and Stix, J. (2000). Encyclopedia of volcanoes. New York: Academic Press.

Settle, M. (1979). The structure and emplacement of cinder cone fields. American Journal of Science, 279(10), 1089-1107. doi: 10.2475/ ajs.279.10.1089.

Streckeisen, A. (1979). Classification and nomenclature of volcanic rocks, lamprophyres, carbonatites and melilitic rocks. Recommendations and suggestion of the IUGS Subcommission on the Systematics of Igneous Rocks. Geology, 7(7), 331-335. doi: 10.1130/0091-7613(1979)7<331:CANOVR>2.0. $\mathrm{CO} ; 2$.

Velandia, F., Ferreira, P., Rodríguez, G., y Núñez, A. (1996). Memoria explicativa levantamiento geológico de la Plancha 366 Garzón. INGEOMINAS, Informe 1321, 122p. Bogotá.

Velandia, F., Ferreira, P., Rodríguez, G., y Núñez, A. (2001). Levantamiento geológico de la Plancha 366 (Garzón). Escala 1:100.000. INGEOMINAS. Bogotá.

White, J.D.L., and Houghton, B.F. (2006). Primary volcaniclastic rocks. Geology, 34(8), 677-680. doi: 10.1130/G22346.1.

Wood, C.A. (1980). Morphometric analysis of cinder cone degradation. Journal of Volcanology and Geothermal Research, 8(2-4), 137-160. doi: 10.1016/0377-0273(80)90101-8. 
Zuluaga, I., and Borrero, C. (2012). Definition of San Agustin Volcanic Field (SAVF) in San Agustín Archaeological Park, Colombia - South America. Conference Proceedings of the Volcandpark Congress, Olot, España.

\begin{tabular}{c}
\hline \hline Lyna M. Rodríguez \\
ORCID: 0000-0002-8179-7343 \\
John J. Sánchez \\
ORCID: 0000-0002-9024-7554 \\
\hline \hline
\end{tabular}

Trabajo recibido: febrero 27 de 2018

Trabajo aceptado: julio 31 de 2018 